\title{
Teacher's Problems in Developing An Environment- Based Geography Instructional Model to Create A Fun School
}

\author{
Singgih Prihadi \\ Department of Geography Education \\ Sebelas Maret University \\ Surakarta, Indonesia \\ zienov@yahoo.co.id
}

\begin{abstract}
This research is based on the low motivation of students to study geography. Students assume that learning geography is just rote. Teachers also have a big role to design a fun geography instructional. The purpose of this research is 1) to know the problems of teachers in creating a fun geography instructional, 2) to know the problems of teachers in optimizing the utilization of the environment as a source of learning geography. The research method used is descriptive qualitative. Researchers distributed questionnaires to geography teachers in Surakarta. The result of the questionnaire is used as the basis for the discussion to deepen the findings. The results of the research are as follows: 1) Geography teachers are generally trapped in the teaching routine according to the schedule determined without thinking about the variation of the learning model, so the students experience boredom when the learning process, 2) Geography teachers generally do not understand the concept of the environment as a source learning, so that the natural environment around the school is not utilized in geography learning, either as a subject matter or as a place of learning.
\end{abstract}

Keywords - geography instructional; teacher's problem; environment; fun school

\section{INTRODUCTION}

The teacher is a professional educator with the main task of educating, teaching, guiding, directing, train, assess, and evaluate learners in the early childhood education path of formal education, elementary education, and secondary education. Teachers should have the minimum academic qualification of Bachelor, master the competencies (pedagogy, professional, social and personality), are certified educators, healthy physical and spiritual, as well as have the ability to realize the goal of national education. The teacher had a position as professionals. Professional is the work or activity undertaken by someone and being the life source of income requires expertise, finesse, or proficiency that meet certain quality standards or norms as well as the need of the education profession. As professionals, teachers are required to always develop themselves in line with advances in science, technology, and the arts. The conditions and the situation became the cause of each teacher has a difference in the mastery of the competencies required. The mastery of competencies must be balanced with the development of innovation, one of them is how to create a fun learning model. Model-based learning environment was developed so that students gain experience has more to do with the surrounding environment. Willis (2014:140) states that, "Children come from diverse backgrounds, particularly in terms of their access to the environment and technology. It is our job to teachers to help level the playing field and provide all students an eq ual chance to succeed. By integrating these two seemingly an curricular areas we can create an opportunity for young children to become both environmentally and technologically literate". The excerpt explains that students come from different backgrounds and different technology environments, but it is the task of the teacher still facilitates the students to be able to access the science and the environment. Teachers must be able to integrate the environment and technology in the learning process. Learning materials are presented to the students compiled by involving the environment. This means that learning can be done not only in the classroom, but also outside the classroom with the goal of keeping students more comfortable and active in the learning process. Model-based learning environment is implementing the system fun and learning outside of the classroom. Some things to look for in a model-based learning environment that is the content and the learning procedure must comply with the environment, knowledge of the learners provided should give way out in response to the environment. The end result of the process of education and learning is the environment. The benefits will be felt if the learning success of learning can be applied and implemented in the reality of life. This is one of the positive aspects influenced side of model-based learning environment.

As professionals, teachers are also required to develop themselves which coincided with advances in science, technology, and the arts. Become professional teachers do not just sit still sits hand only. Professional teachers should be able 
to do new innovations as well as having the expertise, skills, and know-how. All of that must meet quality standards or norms and require the education profession. The fact is there is not a man who is able to master everything in a variety of fields, as well as a teacher. On the basis of the conditions and the situation of the development of sustainable keprofesian should be established and carried out continuously. Development of sustainable professional can be done one of them through the design of the learning model. Environmentbased learning model is the model that aims so that learners can have a concern for the environment. The use of this learning model can be done with a system of learning beyond the classroom so that students have more experience and the process of learning can be fun. The model of learning with an environmental approach, not a new learning approach, but rather already known and popular, just that is often forgotten. As for the definition of the environmental approach is a learning strategy which utilizes the environment as objectives of learning, learning resources, and a learning tool.

Product model-based learning environment that is developed is inseparable from the values of the teachings of $\mathrm{Ki}$ Hajar Dewantara. This is the merit of a learning model will be developed. Model developed must have relevance to the teachings of $\mathrm{Ki}$ Hajar Dewantara. Alkharusi (2015:45) explained that "Teachers assessment practices have been the focus of much attention for over the past years. However, significant interest in classroom assessment environment is a recent phenomenon. The classroom assessment environment represents an important component of the classroom climate". From the quote can be concluded that the assessment of teachers in the learning process is very important. Character assessment with regard to the preservation of the environment must be made of teachers. The activities of the environmental assessment this is a new experience for teachers. Character assessment with regard to the preservation of the environment would be able to create an atmosphere of learning. Isiaka (2007:105) that "the video is a potential window that can expose the minds and heart of many rural African children to modern Agricultural practices and Environmental concepts, far more than the traditional classroom teacher can achieve. Children and youths are so champions are about with home video films that they are described the US video crazy. Their interest in watching home video films can be exploited in the formal school system in teaching Agricultural and Environmental practices in vivid and entertaining manner". From the excerpt concluded that use of video is very potential for displaying the thoughts and hearts of the students in modern farming practices and environmental concepts. The motivation of children in seeing movies on television are utilized to convey messages to always keep the environment. This method is considered very potential to provide education awareness of preserving the environment. The challenge ahead is how to pack the values into teaching model KH Dewantarabased learning environment so that the output of a school is to give birth to children who are sensitive to the environment in which he is located. Children understand the importance of the synergy between the relationship of human life with the environment. This is in harmony with that presented by Crawford et.al (2015:54) that "as children develop learners and thinkers from birth through high school, it is their teachers (including parents) who help shape their understanding of the world around them directly and, by extension, the world as a whole". The quote can be explained that as the development of children as learners and thinkers since birth to high school, their teachers (including the elderly) who helped shape their understanding of the world directly around them.

\section{MethodS}

Research on the problems of teachers in developing a model-based learning environment for creating a fun school, using qualitative, descriptive methods. This method is actually a part of the model of research and development. According to Borg and Gall (1989:10) explained that in order to develop models of learning have to go through 10 activities, namely preliminary studies, planning research, product development, preliminary tests of the product (one to one evaluation, small group evaluation, field triall evaluation), revision, and implementation. On the model of research and development the adaptation of the Borg and Gall (1989:10) explained that the first step to do is study the introduction. Activities in the study of introduction this is a needs analysis that is identifying the problems of teachers in the development of model-based geography learning environment. To know the problems of teachers in the development of learning models, data collection was done through questionnaires, interviews, and Focus Group Discussion (FGD). The technique of data collection through the questionnaire done by the research team attends to high school in Surakarta to meet the teachers of geography. The research team asked the teachers to fill in the questionnaire and the interview continued in depth. The research team came to the respondent as much as 35 teachers of geography are scattered in various high school in the city of Surakarta. The results of the analysis of the questionnaires and the interviews made draft discussion. Geography teachers in the city of Surakarta is collected in a discussion of activities to do matching of the data questionnaire with interviews, as well as to deepen the data may not have been written on the questionnaire.

Questionnaire for needs analysis includes perception, skill, and the suitability of the curriculum. Perceptions of teachers referred to in this research is the presumption of teacher mastery of concepts and the process of developing a model of learning geography-based environment. The skills of teachers referred to in this research is the ability of teachers in implementing the model of learning geography-based environment in the classroom and outside the classroom. The suitability of the curriculum is referred to in this research is the application of environment-based geography learning model in accordance with the demands of the curriculum of 2013. Product development model of learning procedure consists of 3 stages, namely 1) Design, done to plan and 
design a product model that will be developed; 2) Development, to develop materials supporting the implementation of the model; and 3) Evaluation, conducted to test the feasibility of the product models that are developed. The procedure of product development model is described as follows.

Interview conducted researchers against the geography teachers using guided interview non model. Researchers prepare a latticework of questions that will be presented to the teachers. The interview was conducted in order to get a clear description about the perceptions of teachers, teachers skills, and the suitability of the curriculum toward learning model developed. This interview questionnaire as an escort, to uncover information not obtained from questionnaires. Lattice covering the geography teacher response interview against the learning model developed, the geography teacher of the difficulties faced in the development and application of model-based learning environment, geography teacher feedback about cereal Geography materials provided, feedback on procedures applying geography teacher learning, teacher of geography and the response about the effectiveness of the use of model-based geography learning environment.

\section{RESULTS AND DISCUSSION}

Preliminary studies in the framework of product development model of learning geography-based environment is done by finding data perception, skill, and the suitability of the curriculum. Information from teachers of geography is very necessary to strengthen the consideration of learning products were developed. Through the study of introduction in the form of this needs analysis will facilitate researchers in designing learning model with the expediency principle high. Needs analysis conducted by questionnaire, interview, and focus group discussion goes with effective because the geography teachers city of Surakarta is very active and willing to cooperate. Filling the questionnaire done by braving the geography teachers to school each teacher. At the time of the filling of the questionnaire, the researchers did in-depth interviews to obtain data that is not written on the questionnaire. After the data questionnaire and interview are completed processed then continued with a focus group discussion. Focus group discussion conducted by gathering teachers of geography of Surakarta in a forum discussion is divided into several groups.

In detail the preliminary study produced the following description:

\section{Perception}

Based on the data analysis of perception of teachers, can be known that as much as $45.70 \%$ of teachers have already understood the concept of geography learning models are good; $68.56 \%$ teachers understand that the learning of geography will be more meaningful if linked to the environment; $74.28 \%$ of teachers felt still difficulty getting information about the models of learning geography; $60 \%$ of teachers felt the difficulty of creating an atmosphere of fun when learning geography; $42.85 \%$ of teachers felt that students were less enthusiastic when following learning geography; $40 \%$ of teachers felt the difficulty of applying learning geography by making use of the environment as a learning resource. For more details, presented visually in Figure 1.

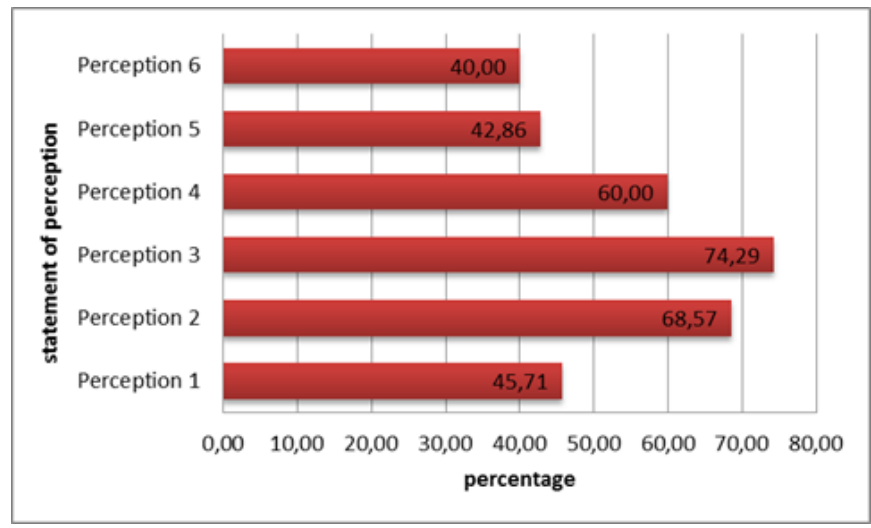

Figure 1. Perceptions of Teachers towards Learning the geography-based Environment

Results of charging the questionnaire and interviews by the geography of the city of Surakarta, known that was still more than half of teachers have not mastered the learning models appropriate to the characteristics of geography. The teachers have yet to master the procedure of learning geography well. Teachers level of understanding already high when doing a geography learning by using learning resource environment. Teachers have considered the design of learning and learning resources messages that match the characteristics of learners. Training on model-based learning environments have never obtained a teacher. Training brings teachers is the introduction of models of learning in General, not specific-based environment. The environment is going to be an interesting learning resource when the teacher was able to capitalize with a creative and innovative. Environmental geography learning will support both in the classroom and outside the classroom. Learners will not feel saturated follow learning geography if the teacher is able to mengkolaborasi the subject matter with environmental learning resources. Teacher innovation need to be developed so that it will produce the learning process interesting, creative and productive.

\section{Skills}

Based on aspects of the skills of teachers, it is known that as many as $68.56 \%$ of teachers have not mastered the learning models appropriate to apply on the subjects of geography; $65.70 \%$ teachers haven't been able to apply geography learning models fit the correct procedure; $51.42 \%$ teacher always associates geospatial information while learning geography; $51.42 \%$ teacher utilizes the environment as the main learning resources in learning geography; $45.70 \%$ of teachers actively create an atmosphere of fun while learning geography; $40 \%$ of the teachers sometimes invites learners learning outside the classroom while learning geography. For more details, presented visually in Figure 2. 


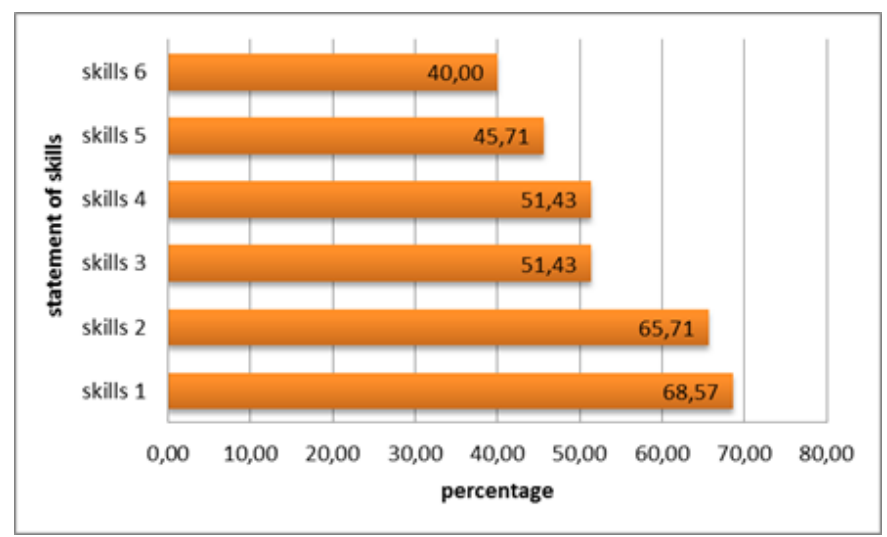

Figure 2. Application Of Model Skill Learning Of Geography

Teacher training on the application of the model of learning that is appropriate to the characteristics of the subject matter of geography still felt very less. Many teachers who have yet to understand the procedures of the particular learning model that suits the subject matter of geography. Teachers already wrote down in implementation plans related learning methods and models of instruction to be used. In practice in the classroom, teachers teach not following procedure models are pre-set. This occurs because of the lack of control of yourself, get lost with the occasional lecture was not in accordance with the subject matter but interesting for learners, and mastery of the skills taught.

\section{Suitability of the Curriculum}

Based on the compliance aspects of the curriculum, can be explained that as much as $57.13 \%$ teachers utilize the environment as a source of learning on all matter of geography in accordance with the demands of the curriculum of 2013; $68.56 \%$ teachers understand that the material should be attributed to the concept of geographical environment; $57.23 \%$ teachers utilizing the learning environment in geography skills to support scientific approach; $57.13 \%$ teachers understand that not all scientific approach skills should be attributed to the learning environment in geography; $68.56 \%$ teachers utilize the environment as a source of learning on all matter of geography in accordance with the demands of the $21 \mathrm{st}$ Century Learning; $54.28 \%$ teachers know that geography textbooks have yet to associate with the concept of the environment; $54.28 \%$ teachers recognize that learning media geospatial has been developed to support the learning geography fun; $68.56 \%$ of teachers have not been active in the development of models and media-based geography learning environment. For more details, visually presented in Figure 3.

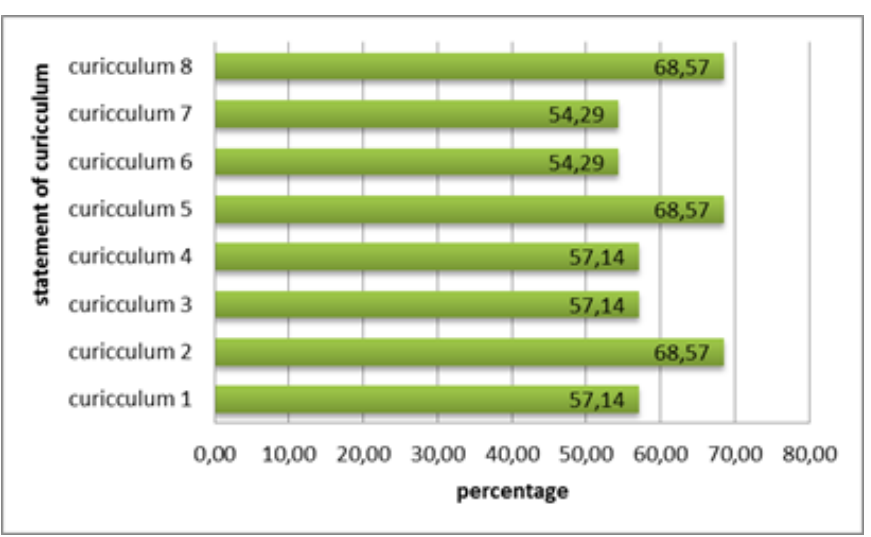

Figure 3. The alignment of the curriculum with Learning the geography of the developed Models

The existence of the environment around schools should be optimally utilized in the process of learning geography. The environment could become a laboratory of geography and geography learning objectives achievement supports appropriate indicators defined in the plan of implementation of the learning. The problem is that there are still many teachers haven't been able to maximize the utilization of the environment laboratory. Curriculum of 2013 requires teachers teaching with scientific approach, relevant to the optimization of the model of learning geography-based environment. Scientific approach covering skills to observe, ask yourself, analyze, try, communicate, can be done with environmentbased learning. Learning outside the classroom needs to be done by the teacher of geography so that learners are not experiencing burnout. The learners as long as it considers that the matter of geography is memorizing the material, caused by the geography teacher who never apply geography learning outside of the classroom. But an awful lot of material can be taught geography outside the classroom, and it is very fun for the learners. Of the three parameters required in the analysis of needs, obtained the information interesting related perception, skill and suitability of the curriculum of the teachers of geography. For more details, visually can be seen in Figure 4.

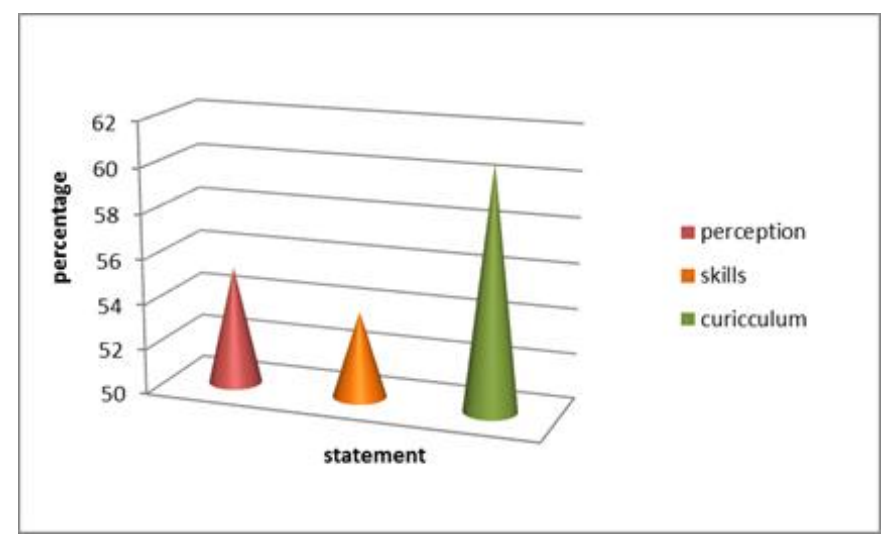

Figure 4. The perception, skill, and the suitability of the Curriculum 
From Figure 4 note that the responses of teachers of geography curriculum in the development of compliancerelated model of learning geography-based environment is very good. As much as $60.71 \%$ teachers already understand and are able to adjust the curriculum with learning the geography of the model being used. Followed by the perception of teachers towards the development of a model of environment-based geography, learning as much as $55.24 \%$ of teachers have a good perception. Related skills focussed learning geography in General, as much as $53.81 \%$ already mastered it well. For the application of model-based learning environment there are still many who have not yet come to know nor master.

\section{CONCLUSION}

From the description of results and discussion of research it can be concluded that in the development of model-based geography learning environment, the teacher already has the perception of a positive and supportive of the process. Support teachers in the development of the learning model is the existence of commitment will be using the product model developed in the learning process. The skills taught are done with the teacher collaboration the environment is already good, but still needs strengthening in order to be more systematic. Employee administration environment as a source of learning geography became part of the implementation of the scientific approach in the curriculum of 2013.

Creative and innovative teacher should be able to develop models of learning geography that uses the environment as part of the model and learning resources. Teachers in sustainable development activities of professional are required to actively doing business in innovative learning. One of them developed a model of learning. In applying the model of learning, teachers should also be good at choosing the model that suits the material presented. The ability for the modification and adaptation of various models of learning will

\section{Acknowledgment}

Researchers say thanks to the Rector of Sebelas Maret University who have given permission and funding in research on the development model of learning needs analysis of geography-based environment for creating fun school. The researchers also say thanks to the teachers of geography of Surakarta who have cooperated to become respondents and the subject in this research.

\section{References}

[1] Alkharusi, Hussain. 2015. An Evaluation of the Measurement of Perceived Classroom ssessment Environment. International Journal of Instruction p-ISSN 1694-609X Vol 8 No 2

[2] Borg, Walter R, Gall, Meredith Damien. 1983. Educational Research : An Introduction. New York \& London : Longman

[3] Crawford, Elizabeth, et.al. 2015. Children as "Solutionaries": Environmental Education as an Opportunity to Take Action. International Journal of Early Childhood Environmental Education, North American Association for Environmental Education ISSN: 2331-0464 Volume 3

[4] Dick W., \& Cary. 2005. The systematic Design of Introduction. Glenview Illionois. Scott Forestman and Company.

[5] Harvey, J. 1998. Evaluation Cookbook. Edinburgh : Heriout - Watt University.

[6] Isiaka, Babaloka. 2007. Effectiveness of video as an instructional medium in Teaching rural children agricultural and environmental sciences. International Journal of Education and Development using Information and Communication Technology (IJEDICT) Vol. 3, Issue 3

[7] Kruger, Marlena and Riana Bester. 2014. Mobile Learning : A Kaleidoscope. The Electronic Journal of eLearning Volume 12 Issue 1 2014, (pp52-76), available online at www.ejel.org

[8] Phillips, Rob. 1997. The Developer's Handbook to In teractive Multimedia (A Practical Guide foe Educational Application). London : Kogan Page

[9] Willis, Jana, et all. 2014. Bridging the Gap: Meeting the Needs of Early Childhood Students by Integrating Technology and Environmental Education. International Journal Early Childhood Environmental Education EISSN 2331-0464 